ojs.uv.es/index.php/qdfed

Rebut: 25.05.2021. Acceptat: 09.07.202I

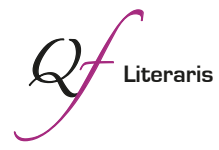

Per a citar aquest article: Del Arco Blanco, Miguel Ángel. 202I. "Los grandes estraperlistas. Imágenes, deformaciones y silencios en la propaganda, cine y novela de la posguerra franquista". Quaderns de Filologia: Estudis Literaris XXVI: 6I-84.

doi: $10.7203 /$ qdfed.26.22098

\title{
Los grandes estraperlistas. Imágenes, deformaciones y silencios en la propaganda, cine y novela de la posguerra franquista ${ }^{\mathrm{I}}$
}

\author{
The great blackmarketeers. Images, deformations and silences in the propaganda, \\ cinema and novels of the Francoist post-war
}

\author{
Miguel Ángel Del Arco Blanco \\ Universidad de Granada \\ maarco@ugr.es
}

Resumen: La política autárquica del régimen franquista dio pie al surgimiento del mercado negro, a la brutal inflación de los precios y al desabastecimiento alimenticio que trajeron la hambruna al país tras i939. En todo ese mundo, hubo unos beneficiarios: los grandes estraperlistas. Fueron personas afines al régimen o pertenecientes a él, que gozaron de la tolerancia de las autoridades y tenían los contactos suficientes para desarrollar sus negocios con impunidad. Sin embargo, la representación que se hizo de ellos por parte de la propaganda del régimen distó mucho de la realidad. Este trabajo pretende reflexionar sobre las narrativas que el franquismo construyó sobre los estraperlistas. Para ello recurrimos a la propaganda, al cine y a la novela de la época. En todas estas fuentes se construyó una imagen de los estraperlistas como malos patriotas, vinculados con el pasado republicano e identificados con el común de la población, confundiendo fenómenos completamente distintos como el pequeño y el gran estraperlo. Aquellas imágenes no eran más que una deformación de la realidad propiciada por la dictadura, que ocultaban palpables silencios sobre quiénes eran realmente los responsables de esos suculentos negocios y lo cercanos que estaban a las esferas de influencia del "Nuevo Estado". Palabras clave: estraperlo; hambre; corrupción; franquismo; propaganda.

Abstract: The autarkic policy of the Franco regime led to the emergence of the black market, price inflation and food shortages that brought famine to the country after I939. However, there were some beneficiaries: the big black marketers. They were people related to the regime

\footnotetext{
${ }^{I}$ Proyecto realizado con la Beca Leonardo a Investigadores y Creadores Culturales 2020 de la Fundación BBVA. Además, el trabajo se enmarca en el proyecto de investigación "La hambruna española: causas, desarrollo, consecuencias y memoria (1939-1952)", financiado por el Ministerio de Economía y Competitividad (MINECO) (PID20I9-Io9470GB-Ioo / AEI / IO.I3039/50IIOOOIIO33.
} 
or belonging to it, who enjoyed the tolerance of the authorities and had enough contacts to carry out their businesses with impunity. The regime propaganda depicted them in a distorted way. This work aims to reflect on the narratives that the Franco regime built on the black marketers. For this purpose, we analyse propaganda, cinema and novels of post-war years. In all these sources, an image of the black marketers was built as bad patriots, linked with the republican past and identified with the common population, completely confusing different phenomena such as the small and the big black market. Those images were nothing more than a deformation of reality, which hid palpable silences about who were responsible for these succulent businesses and how close they were to the spheres of influence of the "New State".

Keywords: black market; famine; corruption; Francoism; propaganda.

\section{Introducción}

"No podemos callar. No debemos callar por más tiempo. Llegan hasta nuestros oídos los clamores de la multitud". Con estas palabras se expresaba en I950 en una carta pastoral dirigida a sus fieles el entonces obispo de Solsona, Vicente Enrique y Tarancón. Evidenciaba las dificultades y la desesperación de las clases bajas y medias españolas y responsabilizaba a los estraperlistas de lo sucedido: "no son pocos los que se han enriquecido desaforadamente en estos últimos años, no existen privaciones.... Pero esas risas y esas alegrías de unos no pueden apagar los clamores de la muchedumbre que sufre hambre y que vive en la miseria". Tras la guerra el "pueblo español" había afrontado "con decisión y alegría aquellas privaciones y aquellos sacrificios que se nos imponían por necesidad". Pero el hambre continuaba: "han pasado más de diez años desde entonces" y durante este tiempo "son bastantes los que se han aprovechado de la escasez para hacer grandes negocios" (Enrique y Tarancón, I950: 3, 9-Io,I4). Aquellas palabras denunciaban a aquellos que se aprovechaban del hambre y de la escasez de posguerra y, mediante su participación en el mercado negro, lograban grandes beneficios. Eran los grandes estraperlistas.

La posguerra española fue una época de corrupción sin precedentes. Los grandes precios alcanzados por los productos de primera necesidad durante aquellos años beneficiaron especialmente a los grandes estraperlistas, quienes, en el sector agrícola, industrial o comercial, se encontraban próximos al régimen. Grandes propietarios, comerciantes o industriales. Pero también diversos intermediarios con conexiones en la administración franquista o, directamente, pertenecientes a ella (militares, falangistas, funcionarios, políticos, etc.), lograron enriquecerse a costa del hambre y la desesperación de las clases más humildes (Claret, 20I9). Mientras que estas últimas acudían 
al mercado negro para tratar de alimentarse o ganar algo de dinero con el que poder comprar productos que habían subido de precio, los grandes estraperlistas se enriquecían de forma ilícita y utilizaban la escasez como toda una oportunidad para agrandar su economía y patrimonio. Así, la carestía tuvo un anverso y un reverso: el de hacer que las clases bajas luchasen por su supervivencia, mientras que algunas personalidades afines al franquismo se enriquecían a costa de ella. El hambre y el estraperlo iban así de la mano y ayudaron a consolidar y perpetuar el franquismo: el hambre propiciaba la desmovilización social de una población preocupada por sobrevivir, mientras que el gran estraperlo garantizaba el apoyo de determinados grupos sociales a la dictadura (Barciela, I989, I998; Christiansen, 2002; Cobo Romero, Del Arco Blanco \& Ortega López, 20II; Del Arco Blanco, 20I8; Román Ruiz, 2020a).

El estraperlo fue el ejemplo más evidente del fracaso de la política económica autárquica, adoptada tras la guerra por el franquismo. La autarquía dio pie al surgimiento del mercado negro, a la brutal inflación de los precios y al desabastecimiento alimenticio que trajeron la miseria y la escasez al país tras I939. En la cúspide de la pirámide de la corrupción de los años cuarenta se encontraban los grandes estraperlistas. A través de sus grandes transacciones ilegales acumularon riqueza y poder. Frente a ellos restaba la figura de los pequeños estraperlistas, que participaban en el mercado negro para aliviar su situación desesperada. Mientras que los grandes estraperlistas gozaron de la tolerancia e inhibición del régimen, aquellos que practicaban el estraperlo de supervivencia fueron perseguidos por las autoridades. Se construyeron así dos contrafiguras en los años del hambre: la de los verdaderos responsables del aumento del coste de vida, de la especulación y de la escasez, los grandes estraperlistas; y la de los pequeños estraperlistas, chivos expiatorios de una corrupción que, para ellos, era forzada para tratar de alcanzar la supervivencia.

El fenómeno del estraperlo ha recibido amplia atención por parte de diversos investigadores. Especialmente tras la muerte de Franco comenzaron a aparecer trabajos que hablaban de él (Clavera, I976; Barciela, i98I; Naredo, I98I). Hoy día conocemos su uso cotidiano durante la posguerra, su funcionamiento, se ha estimado su impresionante volumen o los astronómicos precios que alcanzaron algunos de los productos; también se ha puesto de manifiesto la implicación de los apoyos sociales del régimen en este tipo de prácticas, lo que explica la estabilización de la dictadura así como la persistencia de la política autárquica; e incluso se ha evidenciado que fue un arma de represión contra los más desfavorecidos, puesto que el pequeño estraperlo fue duramente perseguido por las autoridades franquistas. Conocemos bastante del 
pequeño estraperlista: se trataba de mujeres solas o viudas, ancianos, niños $u$ hombres sin trabajo, pertenecientes a clases bajas y golpeadas por la guerra y la represión. No ha recibido tanta atención, en cambio, la figura del gran estraperlista, verdadero contrapunto del negocio del mercado negro (Abella, 2008; Barciela, I98I, 2003; Almodóvar, 2003; Barranquero Texeira \& Prieto Borrego, 2003; Del Arco Blanco, 20Io; Rodríguez Barreira, 20I2).

Por todo ello, este trabajo pretende detenerse en las narrativas que el franquismo construyó sobre los grandes estraperlistas durante la posguerra (I939-I952). En primer lugar, analizamos la imagen del estraperlista en la propaganda del franquismo, centrándonos especialmente en la prensa. En segundo lugar, nos detenemos en reconstruir cómo era representado el estraperlista en el cine y en la literatura de la época. Terminamos con unas conclusiones. Para lograr nuestros objetivos debemos abordar el fenómeno del estraperlo como un todo, puesto que es imposible acercarnos al gran estraperlo y a sus protagonistas sin el contrapunto del pequeño estraperlo. Trataremos de demostrar que, para el franquismo, la figura del gran estraperlista fue un auténtico tabú. No toleró que en la prensa, el cine o en la literatura se dibujase una imagen precisa de él. Tampoco que se le relacionase con el régimen o con sus instituciones. Para ello planteó la lucha contra el mercado negro y el acaparamiento como una continuación de la "Cruzada" contra los "malos españoles", de manera que se inhibía de cualquier responsabilidad o vínculo con el gran estraperlo. Además, la dictadura englobó el gran estraperlo dentro del fenómeno general del estraperlo, sin diferenciarlo del practicado por las clases humildes para salir adelante. Se cinceló así una imagen de los estraperlistas como malos patriotas, vinculados con el pasado republicano o incluso con lo extranjero, confundiendo deliberadamente fenómenos completamente distintos como el pequeño y el gran estraperlo. Aquellas imágenes no eran más que una deformación de la realidad, que ocultaban palpables silencios sobre quiénes eran realmente los responsables de esos suculentos negocios y lo cercanos que estaban a las esferas de influencia del "Nuevo Estado", pero también el sufrimiento, la necesidad y la represión socioeconómica que se cernió sobre las clases más bajas.

\section{Los grandes estraperlistas en la propaganda del régimen de Franco}

Durante la larga posguerra (I939-I952), España se vio envuelta en una escasez sin precedentes. Hace tiempo que los historiadores demostraron que el 
hundimiento de la economía española en la agricultura, industria y comercio se debió a la política autárquica adoptada voluntariamente por el "Nuevo Estado" (Maluquer De Motes, 20I4). Sin embargo, el franquismo recurriría durante sus casi cuatro décadas de existencia a una serie de justificaciones para explicar el hambre y el estancamiento económico. Primero fueron las destrucciones de la guerra, a las que se culpó especialmente a los "rojos". Después llegaría el aislamiento internacional (primero durante la Segunda Guerra Mundial y, al término de esta, por el cerco al que se vio sometido el régimen). Y finalmente también se recurrió a la "pertinaz sequía", otro eslogan justificativo de la propaganda franquista. Todas estas justificaciones colmaron los discursos oficiales del régimen que, a través de una implacable censura previa intervino sobre cualquier aspecto que pudiese abordar la crítica realidad social de "los años del hambre", y por supuesto otros aspectos ideológicos y políticos que pusiesen en cuestión a la dictadura (Sinova, I989: 246-252; Del Arco Blanco, 2020).

Ese es el contexto en el que debemos entender la imagen que la dictadura ofreció sobre el fenómeno del estraperlo y, también, de los estraperlistas. Algo de lo que ni el "Nuevo Estado", ni Franco, ni sus hombres, eran responsables. Se presentaba como un fenómeno ajeno a la voluntad (y participación) de las personas cercanas o afectas al régimen. Una imagen, como veremos, en la que deliberadamente se simplifica bajo la imagen del "estraperlista" un fenómeno poliédrico como fue el estraperlo, sin diferenciar sobre las clases sociales (acomodadas o pobres) que lo desarrollaron, ni sobre sus motivaciones (enriquecimiento o supervivencia), ni de los medios que utilizaron para desarrollarlo, ni tampoco sobre cómo fueron perseguidos (inhibición en el caso de los grandes estraperlistas y persecución brutal hacia los pequeños).

Paradójicamente, al poco de terminar la guerra civil se culpó del estraperlo a los republicanos (Campos Posada, 2020: 90-93). Ellos, como representantes de la "anti-España" eran los responsables de la corrupción y del sufrimiento de los españoles. Ramón Serrano Súñer, cuñado de Franco y uno de los personajes más relevantes de la dictadura en sus primeros años, vertió estas opiniones en sus memorias, publicadas en diversas ocasiones. En la última edición (20II), señalaba que los republicanos, además de los "destrozos" de la guerra, dejaron un "legado de ruina económica y en cierta medida de hábitos de inmoralidad y corrupción que en tiempos posteriores" que darían lugar al fenómeno conocido como "estraperlo". Para Serrano, este tráfico ilegal de materias alimenticias "fue obra de la zona roja”, surgió allí "como una defensa natural de la gente contra la escasez y el desastre de la economía". Tras 
I939 "se extendió aquí a tantos otros tráficos y especulaciones, realizado impunemente desde posiciones ventajosas". Se transmitía así una imagen por la cual los republicanos, antiespañoles, con una moral materialista y fijada en el lucro individual, propiciaron y protagonizaron este tipo de prácticas en una España "sana" (Serrano Súñer, 20II).

Este tipo de argumentos no fue exclusivo del falangista y pronazi Serrano. En I942, la publicación oficial Alimentación Nacional insistía en similares afirmaciones. Durante la guerra no hubo ni escasez ni estraperlo en la "Zona Nacional", donde se mantenía un "justo equilibro en el abastecimiento y un nivel adecuado en los precios" gracias al "patriotismo de todos". Pero con la "victoria, al unir las dos zonas, fue aprovechada por los enemigos de España para extender las lacras de la zona roja, cuyos procedimientos nefastos prendieron en todas las almas ruines. Ocultación y 'straperlismo' fueron las causas, entre otras, que destruyeron el equilibrio económico, y el mercado negro impuso sus trágicos zarpazos sobre las clases humildes, e intensamente en las zonas de hambre" (Comisaría General de Abastecimientos y Transportes, I942: I).

La prensa diaria regional de posguerra calca estas visiones. En I942, el editorial de un periódico falangista de Granada reflexionaba sobre la naturaleza del lucro y la especulación. La explicación de este estaba en la "Cruzada" y en las prácticas de la "zona roja", y se afirmaba que "el lucro tenía rienda suelta en la otra zona" y que "ningún español bien nacido abrió en ella tienda de mercader, ni consideró la tierra española como un zoco innoble" (Patria, 28-4-I942).

$\mathrm{Si}$ en el origen del estraperlo se encontraban los republicanos, en aquella retórica de victoria enarbolada por el régimen en sus primeros "años triunfales", era lógico que se proclamase entonces la necesidad de continuar la lucha. Esta interpretación era coherente con la forma en la que la dictadura y sus partidarios entendían la Guerra Civil. Esta era concebida como una "Cruzada” por recuperar y salvar a la nación española de sus enemigos (internos y externos) (Núñez Seixas, 2006; Rodrigo, 2013). Ahora, en la posguerra, esa narrativa se aplicará al estraperlo, considerándolo otra batalla más que debía ser combatida por los "verdaderos españoles". En efecto: "los enemigos de siempre cuando se les cierra un camino eligen otro, subrepticio y fraudulento, para atacar la fortaleza". Era necesario continuar "nuestra cruzada y lucha sin cuartel" contra el enriquecimiento "a costa nuestra", haciendo frente a esas "fieras monstruosas que arrebatan con sus garras el producto entero de nuestro esfuerzo y labor" (Patria, I8-4-1942). Para esta "nueva cruzada" se convocaba "otra vez a todos los hispanos" para "hacer desaparecer en el más 
breve plazo posible esta legión de mercaderes que se ha instalado en el templo de la Patria" (Patria, I8-4-I942).

Evidentemente, esta apelación a continuar la batalla contra los estraperlistas perseguía exonerar a la dictadura y a sus hombres de cualquier responsabilidad, negando así que los grandes estraperlistas fuesen hombres cercanos al régimen. En consecuencia, el franquismo dirigió todos sus esfuerzos propagandísticos a dejar claro que luchaba de manera incesante contra el estraperlo. De hecho, en I94I se endurecieron las penas para aquellos que participasen en él, hasta el punto de poder llegar a imponer la pena capital (Ley de 24 de junio de I94I, BOE 27/6/I94I, y la Ley de I6 de octubre de I94I, BOE 2I/IO/I94I).

Algo que tendrá un efecto contrario al esperado: al aumentar las penas impuestas, los precios subieron, por lo que aumentaron el coste de vida y las dificultades de las clases con menor poder adquisitivo. Esta campaña no logró el descenso del coste de vida, pero con ella la dictadura se exculpaba a sí misma y a sus partidarios del negocio del gran estraperlo, escondiendo quién estaba detrás de este. Con motivo de este endurecimiento de las penas, en las publicaciones oficiales se dejaba claro que "el estado nacional sindicalista y su Caudillo van a demostrar a todos los españoles que están dispuestos a evitar el lucro inmoral y a cortar la actividad perniciosa de un grupo de malos patriotas" (Comisaría General de Abastecimientos y Transportes, I942: 2)². Se salía al paso, como se afirmaba entonces, de aquellos que "achacaron el mal que ellos produjeron a las clases directoras obstinadas". Se anunciaba incluso el final del estraperlo, y un articulista de un periódico de Málaga anunciaba que el "estado de cosas creado por esta chusma logrera" terminaría "para siempre mediante el castigo ejemplar" por la aplicación del código de justicia militar y de la pena de muerte (Nogueras, I94I; Diario Jaén, I94I).

Sin embargo, el estraperlo no terminó en I94I. Prosiguió durante todos los años cuarenta. Era un fenómeno vinculado a la política intervencionista autárquica y, por eso mismo esta no fue abandonada hasta que la economía española estaba agotada a comienzos de I95I y la supervivencia del régimen corría peligro. Haberlo hecho antes hubiese puesto fin al lucro y enriquecimiento de algunas destacadas personalidades y grupos sociales afectos al franquismo. Por todo ello, el régimen fue cambiando su propaganda sobre el estraperlo: conforme el fin de la Guerra Civil se alejaba, era cada vez más difícil identificar explícitamente a los republicanos con el estraperlo.

\footnotetext{
${ }^{2}$ La cursiva es nuestra.
} 
Así, poco a poco se abrieron paso explicaciones distintas y más ambiguas. La más común era tildar a los estraperlistas de "malos españoles", sin apuntar necesariamente a su pasado republicano. Eran seres desalmados, antiespañoles, que nada tenían que ver con el Estado:

[Se trata de] cuatro desaprensivos, traficantes sucios, pescadores a río revuelto, parásitos (...). Nada les preocupa, nada les interesa que no sea el vil negocio del oro. Son alimañas que se deslizan en la oscuridad, cazando a sus víctimas que, en esta ocasión, es la raza y la vida de su pueblo (Villarejo, s. f.).

Otra vez se encontraba un chivo expiatorio para alejar las sospechas de la población sobre los grandes negocios que militares, políticos, falangistas y otros jerarcas del régimen protagonizaban en los años del hambre. En cambio, los verdaderos españoles no tenían nada que ver con el estraperlo. Ellos poseían las virtudes espirituales de la nación, cifrada por el franquismo en la capacidad de sacrificio, entrega y rigor espiritual. En aquellas horas difíciles de posguerra, a los buenos españoles se les podía "exigir grandes acciones" que realizarían gustosos "por su Patria”: entre ellas, la frugalidad era algo propio de los buenos españoles: "la disciplina alimenticia en la mesa, frente a la tiranía del estómago, es privilegio de un ser culto, patriota y, sobre todo, moral" (Publicación de la Comisaria General de Abastecimientos y Transportes, I942: I ).

En cambio, los "malos españoles" eran identificados como seres amantes del materialismo, sin valores patrios, que velaban por su lucro personal. Esto llevó a que en algunos rotativos identificasen esas prácticas con lo judío. Un periódico era explícito al respecto:

¿De dónde ha salido, pues, esta calaña inmunda que hoy tiende sus manos de presa sobre el cuerpo de la Patria? ¿De dónde este tropel confuso que hoy vende todo por treinta dineros y de atropella para obtener el mayor botín? ¿Cuál ha sido el origen de este brutal materialismo que hoy mancha con sus huellas los caminos limpios de nuestra madre España? Todo lo que rechazamos airadamente a golpe de fusil y con la recta dialéctica de nuestras bayonetas parece volver ahora enmascarado bajo la técnica judía del negocio sucio, donde se obtienen beneficios del quinientos por ciento, donde se multiplican milagrosamente los capitales, donde se elevan como la espuma lo peor de España (Patria, 23-4-I942).

Estos discursos identificaban el judaísmo y el comunismo como los enemigos del régimen y los vinculaban con los protagonistas últimos del gran 
estraperlo, enlazando con una tradición de antisemitismo de parte de las derechas españolas (Rohr, 2008; Preston, 20II: 7I-92). Lo reconocía un artículo incluido en el diario falangista Patria: los enemigos eran los judíos y los marxistas que, coaligados, proseguían la batalla por otros medios: "el negocio abusivo". Este era el "instrumento de disociación que hoy esgrime en España el comunismo y judaísmo internacionales" (Patria, 28-4-I942).

Algunas de las diatribas contra la "anti-España" se dirigieron, curiosamente, a los labradores del mundo rural. En algunas publicaciones se les acusaba de haberse "convertido en comerciantes abusivos de los productos del campo" y era necesario señalarlos como "malos españoles" que hacían estraperlo "con lo más sagrado, que es el pan de los españoles” (El Duende de la Alquería, I94I). De la misma opinión era Rufino Beltrán Vivar, comisario general de Abastecimientos y Transportes y máximo responsable del abastecimiento en el país. Para él, la "ocultación de productores es traición a España": eran ellos los que harían "que comas o pases hambre", por lo que, empleando un exaltado discurso nacionalista, animaba a la población a denunciar: "tú tienes el deber de no consentir la ocultación. Piénsalo y ¡Arriba España!” (Sur, I94I).

Las acusaciones nacionalistas a los productores agrícolas escondían, en realidad, la complejidad del fenómeno del estraperlo, además de silenciar a algunos de sus protagonistas. Como es sabido, los agricultores eran tan solo el primer eslabón de la cadena del estraperlo. Eran ellos los que cultivaban los productos alimenticios intervenidos (trigo, leguminosas, aceituna, etc.). Muchos de ellos, especialmente los más modestos, esquivaban las entregas obligatorias de su producción al Estado, con el fin de alimentar a sus familias, asegurar la siembra de la siguiente cosecha o, también, canalizar parte de su producción en el mercado negro (Del Arco Blanco, 2007: I62-165). Pero los grandes negocios se producían entre los grandes propietarios que, con una producción mucho mayor y con la tolerancia de las autoridades, se lucraban en grandes transacciones (Barciela, I998: 83-96). También participaban del gran estraperlo los comerciantes que transportaban el trigo, aquellos industriales que los transformaban (caso del aceite) y, por supuesto, los que los vendían. De esta forma, que el franquismo denunciase como estraperlistas a los labradores del mundo rural era, también, una exculpación de sí mismo y de buena parte de los grupos sociales que participaban en el negocio y que se lucraban de él. La figura del gran estraperlista seguía siendo borrosa en la propaganda franquista.

La concepción del estraperlista como mal español se mantuvo en el tiempo. No obstante, la propaganda franquista se fue adaptando a las nuevas 
circunstancias históricas. Tras el fin de la Segunda Guerra Mundial los discursos oficiales insistirán una y otra vez en que el estraperlo no era exclusivo de España, sino que era un "fenómeno general, amplísimo y de vasto alcance", que "no deja país tranquilo ni pueblo sano": "las garras del estraperlo se extienden por todos los mercados para empobrecerlos y encarecerlos, lo mismo en España que en Portugal, que en cualquier otro país" (Comisaría General de Abastecimientos $Y$ Transportes, I942: I). Tras cada viraje en la retórica del régimen, tras cada justificación se escondía su propia exculpación: el relato de situaciones todavía más agudas en otros países despejaba cualquier sospecha sobre las políticas del régimen y de sus hombres en el estraperlo hispano.

Este tipo de explicaciones permitía a la narrativa oficial identificar a los grandes estraperlistas con extranjeros, haciéndoles responsables no ya de lo que sucedía en España, sino de las dificultades de toda Europa tras el fin del conflicto mundial. La revista Semana, cuyos lectores pertenecían especialmente a las clases acomodadas, dibujó entonces en sus páginas el perfil de los grandes estraperlistas. Por ejemplo, en noviembre de I945 desvelaba quién era el "rey del estraperlo": se trataba de "M. Grüters", verdadero dominador del mercado negro "de la mitad de Europa". Junto con otros campesinos detenidos en Viena, era responsable de numerosas "fechorías" como "jefe alemán de la industria agrícola": una vez detenido, declaró tener en su poder "900 sortijas de oro y cuatro millos en billetes de banco, de las monedas más estimadas en estos instantes” (Semana, 27-II-I945). Estas noticias evadían, una vez más, cualquier responsabilidad en el gran estraperlo de los jerarcas del régimen, además de subrayar que fuera de España el mercado negro era superior y más importante.

Evidentemente, no era creíble responsabilizar siempre del estraperlo a los extranjeros. Por eso persistieron las explicaciones que señalaban a los responsables de estos negocios dentro del país. Continuaron las denuncias de ellos como malos españoles, pero se abrieron paso justificaciones que subrayaban la crueldad de los estraperlistas y el dolor que causaban. Esto, en boca de algunas autoridades del régimen, parecía despejar otra vez su responsabilidad, así como manifestar que, irónicamente, estaba del lado de los más humildes. Fue el caso del gobernador civil de Jaén, quién en I946 culpaba de la espectacular elevación de precios al "afán de algunos traficantes sin alma, a quienes solo guía un deseo de lucro egoísta, aún a costa del hambre de las clases humildes y de las dificultades de la clase media" (El Ideal [edición Jaén], 24-02-I946). De la misma creencia era Torcuato Luca de Tena que, en un editorial de $A B C$ de I947, calificaba a los estraperlistas de "murciélagos de la sociedad": pese a los 
desvelos de las autoridades por cazarlos, como los murciélagos disponían de un "radar" para sus negocios y acaparamientos, "salvando de todos los obstáculos que las autoridades ponen en su ambicioso revolotear", ensombreciendo "con sus alas extendidas los cielos y los campos de España" (ABC, 25-IO-I947: 3).

Es necesario insistir en una característica de los discursos oficiales del franquismo respecto al gran estraperlo: su disolución (e indiferenciación) dentro de todo el complejo fenómeno del mercado negro. En ningún momento la dictadura distinguió en su propaganda entre grandes o pequeños estraperlistas, y ocultaron de este modo la realidad de posguerra y las motivaciones de unos y otros para delinquir. Como ya apuntamos, el gran estraperlo tenía como fin el lucro y el enriquecimiento. En cambio, el pequeño estraperlo era una de las pocas alternativas que tenían las clases más bajas para sobrevivir y escapar de los efectos de la terrible política autárquica. En efecto, muchos de los más pobres, sin acceso a los productos básicos, con un racionamiento miserable, sin trabajo o con salarios congelados, tuvieron que hacer frente a la escasez y al espectacular aumento de los precios: para lograrlo las pequeñas transacciones en el mercado negro les permitían lograr algo de dinero para sobrevivir y acceder a productos básicos para su alimentación.

Un ejemplo de esta simplificación del estraperlo y de los estraperlistas es la publicación insistente de las listas de sancionados en la prensa diaria que, en teoría, ponían de manifiesto la incansable lucha del régimen contra el encarecimiento de los productos. Se incluían así extensas listas de estraperlistas, en las que se mencionaban su nombre y la multa impuesta. No se aludía a detalles sobre las dimensiones de la transacción, ni de la personalidad de los inculpados. Por supuesto, nunca se aludía a que alguien perteneciente al personal político o la burocracia intervencionista de la dictadura estuviese tras el estraperlo, como sí reconocía la documentación interna del régimen (Ideal, 7-2-I942, I2-2-I942, I4-2-IO42, I5-3-I942, I8-3-I942, 3I-3 I942, I2-4-I942, I44-I942, I5-4-I942)

En ocasiones la prensa pudo ofrecer algún detalle más preciso sobre algún delito de estraperlo. Pero seguía sin definirse la diferencia entre el pequeño estraperlo, de supervivencia y forzado por la necesidad, y el gran estraperlo. Además, cuando se dibujaban perfiles de los responsables, nunca se acerca-

\footnotetext{
3 Un ejemplo de la intervención de las autoridades en el mercado negro puede ser la implicación del gestor del ayuntamiento de Linares en I94I (Archivo General de la Administración, Ministerio del Interior. Dirección General de Administración Local. Caja 2622, Carta dirigida a Ministro de Gobernación, 2-IO-I94I).
} 
ban a los de los verdaderos grandes estraperlistas cercanos al régimen. Así, fue recurrente culpar a campesinos del mundo rural que no entregaban los cupos forzosos asignados por la Administración. En i946, año especialmente duro en cuanto a la escasez, encontramos numerosas noticias de este tipo. En octubre, un periódico granadino anunciaba el arresto de I5 días para un vecino de Bérchules, un pequeño y modesto pueblo de la montañosa comarca de la Alpujarra. Rechazando entregar los cupos asignados, según la noticia, contribuía al encarecimiento de productos y al estraperlo. Se ocultaba, en cambio, que esta actitud podía no estar motivada por la práctica del gran estraperlo, sino sencillamente por las necesidades familiares de un pequeño labrador de una zona rural y marginal. Y por supuesto, se obviaba que aquella producción podría ser vendida a un gran estraperlista que, con los medios y la tolerancia del régimen necesaria, lograse el mayor beneficio con la transacción (Ideal, I5-IO-I946; Ideal [edición Jaén], I-II-I946).

A finales de los años cuarenta hubo un caso de gran estraperlo que fue de conocimiento público, y que saltó incluso a las primeras páginas de los diarios nacionales. Nos referimos al controvertido "Caso del Consorcio de la panadería de Madrid". Incluso entonces, a pesar de la intensa movilización popular provocada, el régimen fue capaz de controlar la situación, eludir responsabilidades y ocultar las vinculaciones de los responsables con el franquismo. A finales de I947, los líderes de esta institución encargada de suministrar el pan y la harina a la capital se vieron envueltos en un caso de estraperlo de grandes dimensiones. Habían desviado toneladas de trigo importado desde Argentina y las habían destinado al mercado negro (Abella, 2008: 158). El malestar de la población fue tal que incluso se produjeron manifestaciones y protestas, y marcharon incluso hasta los edificios de algunos ministerios del gobierno. El régimen utilizó este malestar a su favor: en enero de I948 el Consejo de Ministros impuso una sanción de 28.830 .000 pesetas a los mandos dirigentes, de los cuales, por cierto, no se desveló su identidad. La prensa aseguró que de este modo "la justicia de Franco ampara los intereses del pueblo español” (El Alcázar, 3I-I-I948: I). Además, el 2 de febrero tuvo lugar una masiva manifestación contra los responsables orquestada por la dictadura, que había incluso repartido octavillas el día anterior ( $A B C$, 3-2-I948: I7). Unas 5.000 personas discurrieron por las calles de Madrid, agolpándose frente al Ministerio de Trabajo (Arriba, 3-2-I948). Tras recibir a una comisión, ante la continuidad de los vítores, el ministro falangista José Antonio Girón dirigió unas palabras a la multitud desde el balcón del edificio: "En estos momentos difíciles que atravesamos, debemos unirnos todos los españoles honrados en 
torno al Caudillo para dar la batalla a los vividores y especuladores» (Arriba, 3-2-I948). La identidad y vinculaciones de estos grandes estraperlistas quedaron ocultas y desdibujadas, a pesar de que formaban parte de las instituciones de la dictadura e incluso habían actuado en connivencia de cargos estatales como el Comisario de Abastecimientos de la capital (De Grattis, I969) ${ }^{4}$. El perfil del gran estraperlista debía permanecer oculto.

\section{Los grandes estraperlistas en el cine y en la literatura de los años cuarenta}

Como hemos visto, el régimen y su propaganda hicieron todo lo posible por distorsionar el fenómeno del estraperlo, ofreciendo una imagen simplista del estraperlista que ocultaba la participación de los vencedores en aquel lucrativo negocio. Por ello, no tiene que resultarnos extraño que el cine de posguerra no recogiese demasiado al estraperlo o a sus protagonistas. En él primó el dirigismo ideológico del régimen, especialmente los temas históricos que exaltasen a la nación española recreando un pasado imperial y glorioso. De este modo, predominaron películas ambientadas en el Siglo de Oro, pero también en la propia Guerra Civil, con la que el franquismo se legitimaba. Por supuesto, hubo excepciones y es posible encontrar películas ambientadas en los años de posguerra. Pero se trata de largometrajes que eluden cualquier referencia a las enormes dificultades de la posguerra y, en cambio, plantean historias evasivas donde prima la moral nacional-católica y actitudes conformistas (Caparrós Lera, I983: 31; Evans, I995: 2I5; Crusells Valeta, 20I9; Sánchez Biosca $\&$ Tranche, 2006). Esta renuncia a reflejar la realidad social era coherente con la sostenida en el noticiario oficial del régimen proyectado en las salas de cine antes de cada sesión, más preocupado de difundir una memoria oficial de la guerra civil, así como la ideología o propaganda del "Nuevo Estado" (Sánchez Biosca \& Tranche, 2006).

Por todo ello, es difícil encontrar películas en el cine de posguerra donde el estraperlo o los estraperlistas sean reflejados. A continuación, nos detendremos en dos: Ella, él y sus millones, donde el estraperlo aparece de manera tangencial, casi silenciada. La otra película de la que nos ocupamos, Surcos, es la excepción a la regla al abordar de forma excepcional aquella práctica social y la dureza de la posguerra.

4 Todo el caso, relatado en tono exculpatorio por uno de los considerados culpables. 
En Ella, él y sus millones (De Orduña, I944) el negocio del estraperlo aparece de manera velada. Narra la historia de Alfonso Salazar, un hombre de negocios que decide emparentarse con la nobleza, para lo que busca una mujer de sangre azul perteneciente a una familia arruinada. El largometraje adopta el tono de comedia y, pese a estar rodada en los años más duros de la posguerra, no hay referencia alguna a la escasez o miseria de entonces. La sorprendente riqueza de Alfonso Salazar no es explicada en ningún momento, y se alude a él como un "notable financiero", caballeroso y educado. Él reconoce que no tiene "las manos manchadas de sangre" y que ha "pasado hambre", pero que "ha triunfado" como "comerciante". Aparece perfectamente integrado en la alta sociedad entre la que se mueve. No se le dibuja en ningún momento como gran estraperlista, a pesar de dejar en el aire el porqué de su fortuna.

Una excepción en el tratamiento del estraperlo y sus actores es Surcos, de José Antonio Nieves Conde (I95I). Se trata de una de las películas más interesantes de posguerra, donde la realidad social de aquellos años se refleja con más claridad. El objetivo del filme era frenar el abandono del campo español y la marcha a la ciudad, en un tiempo en el que, por el estancamiento del sector agrario y las nulas expectativas de futuro en el agro, arrancaba una emigración a las urbes, primero clandestina, después autorizada. De esta forma, con el fin de sostener este discurso agrarista tan grato del régimen de Franco, ante el espectador se presentan todos los males y corruptelas que en teoría residían en el mundo urbano (Alares López, 20II). Ese fin hace que la película recree aspectos de la posguerra completamente inéditos en el cine de aquellos años. La cinta relata la historia de una familia campesina (los Pérez) que llegan a Madrid a tratar de ganarse la vida y mejorar su posición económica. Su supervivencia en la capital se hace cada vez más difícil, e incluso los papeles y roles propios de la tradición empiezan a subvertirse (por ejemplo, la supremacía del hombre frente a la mujer) (Nieves Conde, I951).

La palabra estraperlo aparece varias veces en el largometraje. En el patio de vecinos cuando llegan visitantes y llaman a alguna puerta. En la escena donde en un guiñol la mujer acusa a su esposo de ser un "estraperlista sinvergüenza” por haberse gastado toda la paga en la taberna. Se refleja a la perfección el pequeño estraperlo. Es practicado por el anciano cabeza de familia (Manuel) que, tras no aguantar el ritmo de trabajo en una fundición, se dedica a la venta ambulante de caramelos por calles y plazas, siendo incluso detenido por la policía. También se dedica a esta actividad el hijo mayor (Pepe): con toda claridad se muestra la dureza de la venta clandestina ambulante, afrontando los robos a los que es sometido o la persecución de las autoridades. Este estra- 
perlo es presentado como un paso más en la degradación moral de la familia al llegar a la ciudad. Estas ínfimas transacciones eran en realidad una táctica de resistencia frente a las políticas del régimen, con las que se pretendía sobrevivir a las difíciles circunstancias de posguerra (Román Ruiz, 2015, 2020b; Rodríguez Barreira, 20I3) El filme recrea también la persecución implacable del régimen sobre el pequeño estraperlo: pese a ser el eslabón último de la cadena de las transacciones en el mercado negro, su persecución supuso la incautación de la mercancía, la imposición de multas, el encarcelamiento de los responsables o su envío a los batallones de trabajo (Gómez Oliver \& Del Arco Blanco, 2005).

Pero si por algo llama la atención la obra de Nieves Conde es porque, excepcionalmente, nos ofrece un retrato explícito del gran estraperlista. El gran estraperlista coincide con buena parte de las características que le otorgaba la propaganda franquista; también difiere en algunas, por lo explícito de su representación. Encaja con esa visión de hombre sin escrúpulos, sin valores, materialista y ajeno a la nación española. Es representado por un oscuro personaje, don Roque, que incluso recibe un apodo extranjero: "el Chamberlain". Encarna al nuevo rico de la ciudad, sin escrúpulos, el único personaje con algo de sobrepeso, que se ha enriquecido con el negocio del estraperlo (mediante el transporte o robo de sacos de trigo o harina). Su moral corrupta se extiende a las figuras que le rodean: da empleo a Pepe, el hermano mayor, que acaba encontrando la muerte en gran parte por responsabilidad de don Roque; también protege a la hermana de este, ofreciéndole regalos, convirtiéndola en su querida y deshonrándola (Guerra Gómez, 200I: 234; Marcos, 20I5). No obstante, a pesar de la mordaz crítica del personaje, hay una absoluta desconexión entre este gran estraperlista y las autoridades del régimen. Un régimen que parece no estar presente en la película, más que para detener a los pequeños estraperlistas y al que no se hace responsable de la dureza y miseria de la vida de los protagonistas.

En suma, Surcos nos dice mucho más que otras fuentes históricas del fenómeno del estraperlo. Con su crudeza, con su baile de desgraciados personajes y con su neorrealismo llega a puntos excepcionales. Pero también ostenta notables continuidades con los discursos del régimen. Se representa en ella al pueblo español, identificado como verdadero y honesto cuando proviene del mundo rural, y corrupto y antiespañol cuando se empapa de los valores urbanos. Un pueblo que parece danzar solo por el camino de la miseria, donde el régimen franquista no tiene ninguna responsabilidad ni en la crítica situación social ni en el enriquecimiento de los grandes estraperlistas. 
No encontramos muchas más referencias al fenómeno del estraperlo en el cine de los años cuarenta. Puede aparecer de forma tremendamente tangencial en algún filme, como en Una mujer cualquiera (1949), la historia moralizante de una mujer que se separa de su marido y trata de sobrevivir sola en el oscuro y sórdido ambiente de posguerra, donde se perciben ecos lejanos de estraperlistas moviéndose en la ilegalidad (Rodríguez Fuentes, 20II: 6I). Tenemos que esperar ya a los cincuenta para encontrar alguna referencia más cargada de crítica e ironía, pero también tangencial. Nos la ofrece Luis García Berlanga en dos ocasiones. Primero en ¡Bienvenido, Mister Marshall! (I953), cuando al recibir la visita del delegado del gobierno que le comunicará la llegada de los americanos, el alcalde teme que haya venido para investigar el estraperlo en el pueblo y se disculpa por la menor producción de la cosecha de trigo y de la cría de ganado por las condiciones atmosféricas (Cañaque \& Grau, I993: 24). Varios años después el estraperlo vuelve a aparecer en Calabuch (1956), siendo practicado por algunos vecinos del pueblo donde se narra la historia, ante un guardia civil que mira hacia otro lado. Pero incluso en el sórdido e irónico retrato social del cine de Berlanga, el régimen franquista no permite una aproximación directa y completa del fenómeno.

En definitiva, salvo la excepción mencionada de Surcos, el cine franquista evitó reflejar el fenómeno del estraperlo y las miserias de posguerra, posiblemente por su naturaleza conservadora y por la acción implacable de la censura. No obstante, el tema comenzaría a aparecer cada vez más en el cine más crítico con la dictadura, y lo haría de forma definitiva justo después de la muerte de Franco, en una serie de películas que por fin le dieron cabida recurriendo a la sátira o la denuncia, como pudieron ser Niñas... jal salón! (Vicente Escrivá, 1977), Carne apaleada (Javier Aguirre, 1978) o Las alegres chicas de Colsada (Rafael Gil, I983). La memoria de la corrupción y de los perpetradores salía por fin a la luz (Gustrán Loscos, 20I5: III-II2, I77, 346).

Algo similar puede decirse de la novela de posguerra, a la que queremos dedicar algunas líneas en este artículo. Como es sabido, la mayoría de la literatura publicada en los años cuarenta será de evasión, rehuyendo la realidad social (Barrero Pérez, 1987; Martínez Cachero, 1980). Será solo en las obras del llamado existencialismo en las que se refleje el mundo triste y gris en el que la "Victoria" franquista se impuso, pero en ningún caso reflejan de manera explícita y compleja el fenómeno del estraperlo ni a sus protagonistas 5 .

${ }^{5}$ La familia de Pascual Duarte, publicada por Camilo José Cela en I942 y enmarcada en el tremendismo, tampoco refleja ningún aspecto relacionado con el estraperlo o la política autárquica: 
Detengámonos en un ejemplo de las novelas de evasión. En la mayoría de ellas no hay referencias al estraperlo y, cuando las hay, el fenómeno es reflejado de manera completamente distorsionada. Quizá el mejor ejemplo sea Yo he sido estraperlista (I950), de la novelista Ángeles Villarta. Esta escritora, periodista y jefa de prensa de Auxilio Social, dirigió la serie "La Novela Corta", donde publicaron escritores relevantes como Pío Baroja, Jardiel Poncela, José María Pemán o Wenceslao Fernández Florez. En su pequeña novela, supuestamente autobiográfica, hace un retrato cómico y a la vez cruel del estraperlo. Relata anécdotas y vicisitudes de una mujer que, en el Madrid de posguerra, se dedica al estraperlo. La protagonista aparece descontextualizada: no se explica si se ve obligada a practicarlo por necesidad, cuál es su origen social o la condición o situación de su familia. Así, su figura (extensiva a las estraperlistas) aparece deshumanizada: "todas las que nos dedicamos al estraperlo terminamos con el corazón hecho un buñuelo de viento. Se nos vacía la sangre" (Villarta, I950: I). Por otro lado, se identifica estraperlo solo con pequeño estraperlo. Las protagonistas son siempre mujeres de baja moral o de baja condición social que, en calles, trenes, mercados o pisos, son las responsables del estraperlo y el encarecimiento de productos. Así, se pone el foco especialmente en barrios marginales como Vallecas, donde se denuncia la moral de sus habitantes obviando la pobreza que los asedia. Los grandes estraperlistas sencillamente no existen. Es más, parece que la cadena del mercado negro se limita a esas mujeres que marchan a los pueblos o barrios marginales a obtener productos que luego venden a sobreprecio, causando un terrible mal a la sociedad. No se justifica esta actividad por la desesperación de esas mujeres o la situación socioeconómica de sus familias. Y, por supuesto, el Estado franquista es ajeno a todo aquello: las persigue a través de sus guardias y se esfuerza una y otra vez en suministrar raciones más abundantes. Esta última iniciativa da pie a la queja de una de las estraperlistas que desfila por la novela, que afirma: "No sé qué piensa el Gobierno cuando aumenta las raciones de pan... Echan a perder el estraperlo... Antes daba gusto... En cada barra [de pan] nos quedaban siete u ocho gordas" (Villarta, I950: 5). Se recrea, en suma, un estraperlo ajeno a la realidad social de posguerra.

pero ello es explicable porque las "memorias" del protagonista terminarían en I937, cuando es ajusticiado. Algo similar sucede con la censurada Luciérnagas, de Carmen Martín Gaite, publicada sin cortes en I993: este conmovedor retrato de la realidad social (donde aparece el mercado negro) se centra en la Barcelona de la Guerra Civil. 
Por lo menos en las novelas existencialistas se transmite un pesimismo más acorde con la posguerra y sus dificultades. Buen ejemplo es Nada (I945), de Carmen Laforet y al que se le concedió el primer premio Nadal. Publicada a mediados de los años cincuenta, en el corazón de los años del hambre repleto de cartillas de racionamiento y de alimentos sucedáneos, no contiene una mención explícita a todo aquel mundo de posguerra. De manera intimista se nos narra la juventud frustrada de Andrea, una joven estudiante que se traslada a Barcelona y encuentra un mundo donde sus ilusiones se rompen. Pese a recoger la vida dentro de su casa en la calle Aribau, con sus familiares, e incluso paseos con algunos de sus conocidos, no hay ni rastro de los problemas de abastecimiento, del estraperlo o de los estraperlistas. También en la literatura el estraperlo y sus protagonistas eran un tema vetado (Laforet, 20I3).

La Colmena, de Camilo José Cela, viene a ser la excepción a la regla, como lo fue Surcos en el cine. Ahora bien, tuvo que esperar a I95I para ser publicada, y solo vio la luz en Buenos Aires (Argentina). En España se publicó solo en I955, cuando el gran estraperlo había desaparecido. Recrea de manera realista, sórdida y asfixiante el Madrid de posguerra. Multitud de personajes deambulan por las calles, cafés, pensiones y viviendas humildes con la escasez de fondo, en un ambiente oscuro, de frío y miseria. En aquella sociedad, el estraperlo y los estraperlistas no solo se presienten, sino que forman parte del paisaje. No se alude de forma explícita al gran estraperlo o a quienes lo practicaban. Pero la novela sí evidencia que los más acomodados en aquel difícil mundo practican el estraperlo: así se dice del patrón de un café que "es un hombre de buena sangre, un hombre honrado que hace sus estraperlos, como cada hijo de su vecino". Mario de la Vega, "el impresor del puro", aparece siempre desocupado y haciendo gala de su enriquecimiento súbito, con el que doblega la voluntad de varios personajes desesperados: a algunos les ofrece trabajo e incluso consigue que la desesperada Victorita se le entregue para tratar de salvar a su novio enfermo de tuberculosis. Este estraperlo de los ricos coincide con el pequeño, que hacía posible el abastecimiento de muchos. De este modo, se evidencia que la sociedad tiene que comprar productos en el mercado negro para cubrir sus necesidades alimenticias. Cuando Filo da de comer en secreto a su hermano Martín Marco le reconoce que "pan no hay" y que tienen que comprarlo "de estraperlo para los niños". También está presente la actitud persecutoria de las autoridades sobre el pequeño estraperlo, sin interesarse demasiado por las grandes transacciones: en aquellos años de hambre el guardia Julio García, se declaraba conformista y fiel a las órdenes de sus superiores, reconociendo que así sería "mientras me den de comer 
caliente todos los días y lo que tenga que hacer no sea más que pasear detrás de las estraperlistas". Incluso encontramos una distinción entre el pequeño y gran estraperlo en boca de alguno de sus protagonistas, justificando a la perfección la necesidad de los más pobres de practicarlo y deslizando una crítica hacia el régimen. En una escena, Celestino Ortiz, dueño de un pequeño bar donde duerme por las noches, razona ante un guardia:

Eso de prender a las estraperlistas del Metro, me parece una injusticia. La gente tiene que comer y si no encuentra trabajo, pues ha de apañárselas como pueda. La vida está por las nubes, eso lo sabe usted tan bien como yo, y lo que dan en el suministro no es nada, no llega ni para empezar. No quiero ofender, pero yo creo que el que unas mujeres vendan pitillos o barras no es para que anden ustedes los guardias detrás.

La llegada de los años cincuenta supuso el despertar de una nueva novela, más crítica y atenta a la realidad social. Es entonces cuando comienza a desnudarse de manera más explícita el mundo de posguerra y del estraperlo. Los cuentos de Aldecoa fueron un paso esencial para conocer aquellos duros años, si bien no encontramos referencias demasiado directas a los grandes estraperlistas (Aldecoa, I995). Es Tiempo de Silencio (I995), de Luis Martín Santos, la novela que mejor recrea el hambre y la miseria de los cuarenta en Madrid, estando ambientada en I949; pero tampoco se detiene en los estraperlistas, sus negocios o los vínculos con el gobierno (Martín Santos, I995). Vuelve a demostrarse que la intervención de la censura (y de la autocensura) tuvo mucho que ver en que los escritores de entonces pasasen por alto la corrupción del estraperlo. Por eso, no es extraño que la primera novela que dibuja con sordidez y complejidad el fenómeno del estraperlo sea publicada en 1973 en México: Si te dicen que caí, de Juan Marsé. Tendría que esperar a I976 para ser publicada en España. Aquel desgarrador retrato de la Barcelona de I944 está repleta de suciedad, miseria, hambre y, por supuesto, de corrupción. El pequeño estraperlo está en los personajes desesperados que venden artículos entonces de lujo (café, chorizo). Pero Marsé también retrata el enriquecimiento y la connivencia de las autoridades de la dictadura: un delegado falangista que cobra la cuota de Auxilio Social y la contribución de Falange por todos los bares y a cambio "deja vender rubio de estraperlo": "es uno de ellos, de esos que se dedican a chuparte la sangre, qué le vamos a hacer. Con lo que me sacan, alguno se estará haciendo una torre" (Marsé, I998). Para llegar a este punto, sin embargo, había sido necesario el paso de diversas generaciones y, especialmente, el fin de la dictadura. 


\section{Conclusiones}

Es imposible entender la posguerra española sin tener en cuenta la realidad social, económica y política de los "años del hambre". Fue un tiempo de victoria y de no reconciliación. Años de regresión económica brutal, en la que los indicadores económicos españoles quedaron estancados a niveles de preguerra. Un tiempo en el que parte de la población, especialmente las clases bajas, soportaron una carestía y una miseria sin precedentes. La gravedad de la situación ha justificado que lo sucedido entonces sea calificado como de una hambruna homologable a las que tuvieron lugar en el periodo de entreguerras (Del Arco Blanco, 202I).

La hambruna española tuvo mucho de político. Se ha demostrado que, junto a factores coyunturales (consecuencias de la Guerra Civil), su origen está en el posicionamiento político del franquismo con las potencias del eje y en la adopción de la política económica autárquica. En efecto, la escasez y la intervención económica se retroalimentaron mutuamente, viéndose intensificadas por un fenómeno esencial: el estraperlo. Ante los problemas de abastecimiento, recurrir a él fue el medio que muchos ciudadanos corrientes tuvieron para salir adelante y lograr alimentarse; al mismo tiempo, fue el instrumento para que los grandes estraperlistas y determinadas personalidades cercanas al régimen se enriqueciesen en unos tiempos de escasez. Una mirada al complejo fenómeno del estraperlo produce así contrafiguras: por un lado los perseguidos por el régimen de manera incesante pese a que solo trataban de salir adelante, en una suerte de represión socioeconómica; y por otro lado los grandes estraperlistas, que gozaron de la tolerancia de un régimen de Franco con el que ostentaban fantásticas relaciones y que quedaron impunes, siendo perpetradores del hambre y de la miseria.

Todo ello justifica que el franquismo evitase por todos los medios transmitir una imagen compleja y completa del estraperlo, en la que se percibiese claramente a los grandes estraperlistas. En su propaganda no dejó de ofrecer justificaciones que simplificaban el fenómeno y a sus protagonistas, poniendo en el mismo fiel de la balanza a todos los actores, acusándolos de ser enemigos de la patria y despejando cualquier identificación con el régimen. En el cine y en la novela sucedió algo parecido. El control de estos medios por el "Nuevo Estado" imposibilitaba la creación de películas o novelas que reflejasen la realidad social y delatasen la verdad del estraperlo. No obstante, incluso cuando esto fue posible, la reconstrucción de la corrupción estraperlista se hizo con evidentes limitaciones. El gran estraperlo, por lo que decía de sí 
mismo, fue uno de los mejores secretos guardados por el régimen de Franco. Sin embargo, su realidad se atisba en los documentos internos del régimen $\mathrm{y}$, tras la muerte del dictador, ha sido reflejada por los creadores y rescatada por los historiadores, poniendo por fin sobre la mesa a las contrafiguras de la represión socioeconómica de posguerra.

\section{Bibliografía}

(s.a.) I94I (I3 de noviembre). Acabando con el "estraperlo", el abastecimiento está asegurado. Sur.

(s.a.) I942 (I8 de abril) Patria.

(s.a.) 1942 (28 de abril) Patria.

(s.a.) I945 (27 de noviembre). El rey del gran estraperlo. Semana 301.

(s.a.) 1946 (I de noviembre). Ideal (edición Jaén).

(s.a.) I946 (I4 de octubre). Detenido por no entregar los cupos de cereales y leguminosas. Ideal.

(s.a.) 1946 (24 de febrero). El gobernador civil de Jaén pide la colaboración para evitar el abuso en los precios. Ideal (edición Jaén).

(s.a.) 1946 (7 de febrero). Sancionados por la Fiscalía de Tasas. Ideal (edición Málaga). (s.a.). I94I (2I de octubre). Delitos de acaparamiento, ocultación y venta a precios abusivos se castigarán con el máximo rigor. El Diario de Jaén.

(s.a.). 1942 (28 de abril). Patria.

(s.a.). 1948 (3 de febrero). $A B C$.

(s.a.). 1948 ( 3 de febrero). Arriba.

(s.a.). I948 (3I de enero). El Alcázar.

El Duende de la Alquería. 194I (3I de agosto). ¿Qué pasa?, ¿Qué pasa en el campo?

Abella, Rafael. 2008. Por el Imperio hacia Dios. Crónicas de una Posguerra (1939-1955). Barcelona: Ediciones B.

Alares López, Gustavo. 20II. Ruralismo, fascismo y regeneración. Italia y España. Ayer 83: I27-I47.

Aldecoa, Ignacio. I995. Cuentos Completos (1949-1969). Madrid: Alfaguara.

Almodóvar, Miguel Ángel. 2003. El hambre en España: historia de una alimentación. Madrid: Oberon.

Archivo General de la Administración, Ministerio del Interior. Dirección General de Administración Local. Caja 2622, Carta dirigida a Ministro de Gobernación, 2-IO-I94I.

Barciela, Carlos. I98I. El "estraperlo" de trigo en la posguerra. Moneda y Crédito I5I: I7-37.

Barciela, Carlos. 1989. La españa del estraperlo. En Tuñón de Lara, J. M. \& García Delgado, M. El primer franquismo. España durante la Segunda Guerra Mundial. $V$ Coloquio de Historia Contemporánea de España. Madrid: Siglo XXI. 
Barciela, Carlos. I998. Franquismo y corrupción económica. Historia Social 30: 8396.

Barciela, Carlos. 2003. El lobby agrario en la España franquista. En Toscón Fernández, Glicero \& Sánchez Recio, Julio (eds.) Los empresarios de Franco. Política y economía en España, 1936-1957. Barcelona: Crítica, III-I2O.

Barranquero Texeira, Encarnación \& Prieto Borrego, Lucía. 2003. Así sobrevivimos al hambre. Estrategias de supervivencia de las mujeres en la posguerra española. Málaga: Diputación de Málaga.

Barrero Pérez, Oscar. I987. La novela existencial española de posguerra. Madrid: Gredos. Cañaque, Carlos \& Grau, Maite. I993. ¡Bienvenido, Mr Berlanga!. Barcelona: Destino. Caparrós Lera, José María. I983. El cine español bajo el régimen de Franco (1936-1975). Barcelona: Edicions de la Universitat de Barcelona.

Christiansen, Thomas. 2002. Intervencionismo del Estado y mercado negro en el sector oleícola durante el primer Franquismo. Historia Agraria. Revista de agricultura e historia rural 27: 22I-246.

Claret, Jaume. 2019. Ganar la guerra, perder la paz memorias del general Latorre Roca. Barcelona: Crítica.

Clavera, Juan. I976. El estraperlo en los años cuarenta. Información Comercial Española 5I4: 9I-97.

Campos Posada, Ainhoa. 2020. Madrid o "la capital del espectro": la utilización del hambre como arma de guerra y posguerra por el franquismo. En Del Arco Blanco, M. A., (ed.) Los años del hambre. Historia y memoria de la posguerra franquista. Madrid: Marcial Pons.

Cobo Romero, Francisco; Del Arco Blanco, Miguel Ángel \& Ortega López, Teresa. 20II. The Stability and Consolidation of the Francoist Regime. The Case of Eastern Andalusia, I936-I950. Contemporary European History 20 (I): 37-59.

Comisaría General de Abastecimientos y Transportes. I942. Alimentación Nacional. Madrid: Editorial, 6.

Crusells Valeta, Magí. 20ı9. El cine español en los primeros años de la dictadura de Franco. Entre el entretenimiento y la propaganda. En Lemus López, Encarnación \& Peña, Manuel (eds.) Alianzas y propaganda durante el primer franquismo. Madrid: Alianza, I75-212.

De Grattis, J. I969. Rejas sin votos. El libro áureo del Consorcio de Panadería de Madrid. Madrid.

De Ortuña, Juan (director) \& Echegaray, Alberto; De Ortuña, Juan; Tamayo, Manuel (guión) [DVD]. I944. Ella, él y sus millones. Valencia: Cifesa.

Del Arco Blanco, Miguel Ángel. 2007. Hambre de siglos. Mundo rural y apoyos sociales del franquismo en Andalucía Oriental (1936-1951). Granada: Comares.

Del Arco Blanco, Miguel Ángel. 20I8. La corrupción en el franquismo. El fenómeno del gran estraperlo. Hispania Nova I6: 22I-246.

Del Arco Blanco, Miguel Ángel. 2020. Los años del hambre. Historia y memoria de la posguerra franquista. Madrid: Marcial Pons.

Del Arco Blanco, Miguel Ángel. 202I. Famine in Spain during Franco's dictatorship (I939-I952). Journal of Contemporary History 56 (I): 3-27. 
Del Arco Blanco, Miguel. 20ıo. El estraperlo: pieza clave en la estabilización del régimen franquista. Historia del Presente 15: 65-78.

Enrique y Taracón, Vicente. I950. "El pan nuestro de cada día dánosle hoy" Carta Pastoral. Madrid: HOAC.

Evans, Peter. I995. Cifesa: Cinema and Authoritarian Aesthetics. En Graham, Helen \& Labanyi, Jo (eds.) Spanish cultural studies. An introduction. Nueva York: Oxford University Press, 215-222.

García Berlanga, Luis (director) \& Martín, Leonardo y Flaiano, Ennio (guion). I956. Calabuch. [DVD] Co-producción España/Italia: Águila Films/Films Costellazione.

Gómez Oliver, Miguel \& Del Arco Blanco, Miguel. 2005. El estraperlo: forma de resistencia y arma de represión en el primer franquismo. Studia Histórica. Historia Contemporánea 23: I79-I99.

Guerra Gómez, Amparo. 200I. Las heridas abiertas de la paz. Clases y escenarios sociales de la postguerra en Surcos. Historia y Comunicación Social 6: 229-237.

Gustrán Loscos, Carmina. 20I5. El franquismo en el cine español (1975-2000): la representación cinematográfica de la dictadura franquista (Tesis Doctoral). Zaragoza: Universidad de Zaragoza.

Laforet, Carmen. 20I3. Nada. Barcelona: Destino.

Ley de i6 de octubre de i94I por la que se modifica la de 24 de junio de I94I. Boletín Oficial del Estado, 2I de octubre de i94I.

Ley de 24 de junio de I94I, por la que se reorganiza la Comisaría General de Abastecimientos y Transportes. Boletín Oficial del Estado, 27 de junio de I94I. Capitulo Noveno, disposiciones finales. https://www.boe.es/datos/pdfs/ BOE//I94I/I78/A04706-047I3.pdf

Luca de Tena, Torcuato. I947 (25 de octubre). Los murciélagos de la sociedad. ABC.

Maluquer De Motes, Jordi. 20I4. La economía española en perspectiva histórica. Siglos XVIII-XXI. Barcelona: Pasado y Presente.

Marcos, Marcelino C. 20I5. Estética e ideología en Surcos. España Contemporánea: Revista de literatura y cultura 2-I(24-25) tomo: 209-2IO.

Marsé, Juan. I998. Si te dicen que caí. Barcelona: Plaza y Janés.

Martín Santos, Luis. I995. Tiempo de silencio. Barcelona: Seix Barral.

Martínez Cachero, José María. I980. Historia de la novela española entre 1936-1975. Madrid: Castalia.

Naredo, José Manuel. I98I. La incidencia del “estraperlo" en la economía de las grandes fincas del Sur. Agricultura y Sociedad I9: 8I-I29.

Nieves Conde, Jose Antonio (director) \& Montes, Eugenio (guion). I951. [DVD] Surcos. Barcelona: Atenea Films.

Nogueras, Raúl S. I94I (5 de noviembre). Para los desaprensivos. Sur.

Núñez Seixas, Xosé Manoel. 2006. ¡Fuera el invasor! Nacionalismos y movilización bélica durante la guerra civil española (1936-1939). Madrid: Marcial Pons.

Preston, Paul. 20II. El holocausto español: odio y exterminio en la guerra civil y después. Barcelona: Debate. 
Rodrigo, Javier. 2013. Cruzada, paz, memoria. La guerra civil en sus relatos. Granada: Comares.

Rodríguez Barreira, Óscar J. 20ı2. Lazarillos del Caudillo. El hurto como arma de los débiles frente a la autarquia franquista. Historia Social 72: 65-87.

Rodríguez Barreira, Óscar J. 20I3. Cambalaches: hambre, moralidad popular y mercados negros de guerra y postguerra. Historia Social 77: I46-I74.

Rodríguez Fuentes, Carmen. 20II. Similitudes entre el cine clásico negro y el cine de un autor español de posguerra. En Mateos, Concha; Ardèvol, Alberto \& Toledano, Samuel La comunicación pública secuestrada por el mercado. La Laguna: Sociedad Latina de Comunicación Social, 45-63.

Rohr, Isabelle. 2008. The Spanish Right and the Jews, 1898-1945: Antisemitism and Opportunism. London: Cañada Blanch Centre for Contemporary Spanish Studies.

Román Ruiz, Gloria. 2015. Delinquir o morir. El pequeño estraperlo en la Granada de posguerra. Granada: Comares.

Román Ruiz, Gloria, 2020a. El negocio del hambre. Fraude y corrupción durante la posguerra autárquica en el campo alto-andaluz. Historia Contemporánea, 63: 663-69i.

Román Ruiz, Gloria. 202ob. Franquismo de carne y hueso. Entre el consentimiento y las resistencias cotidianas (1939-1975). Valencia: Universitat de València.

Sánchez Biosca, Vicente \& Tranche, Rafael. 2006. NO-DO. El tiempo y la memoria. Madrid: Cátedra.

Serrano Súñer, Ramón. 20II. Entre Hendaya y Gibraltar (noticia y reflexión, frente a una leyenda, sobre nuestra política en dos guerras). Barcelona: Planeta.

Sinova, Justino. I989. La censura de prensa durante el franquismo: (1936-1951). Barcelona: Espasa Calpe.

Villarejo, Dr. Comentarios higiénicos al estraperlo. Hechos. Revista ilustrada., s. f.: s. f.

Villarta, Ángeles. I950. Yo he sido estraperlista. S. 1.: s. e. 